\title{
Pericardial Cytokine "Storm" in a COVID-19 Patient: the Confirmation of a Hypothesis
}

\author{
Cristian Deana $^{1,5}{ }^{\oplus}$, Luigi Vetrugno ${ }^{1,2}$, Martina Fabris ${ }^{2,3}$, Francesco Curcio $^{2,3}$, \\ Emanuela Sozio ${ }^{4}$, Carlo Tascini ${ }^{2,4}$ and Flavio Bassi ${ }^{1}$
}

Received 26 June 2021; accepted 7 September 2021

\begin{abstract}
Novel Coronavirus Disease in most cases produces mild symptoms which resolve after a few days. Some authors hypothesized that SARS-CoV-2 infection could trigger excessive cytokine production leading to a severe multi-organ disease requiring intensive care admission. Respiratory and neurological symptoms are the most frequently reported manifestation of the disease. Indeed, cardiac involvement is reported mostly as a part of a systemic disease. Few isolated cardiac manifestations of COVID-19 infection have been described. We report herein a case of SARS-CoV-2 related severe isolated pericardial involvement requiring ICU admission due to cardiac tamponade needing urgent drainage. Analysis of pericardial fluid from drainage demonstrated a higher cytokine concentration than blood values. Other causes of pericardial disease, such as autoimmunity, bacterial or other than COVID-19 infection, neoplasms or acute myocardial infarction were also evaluated, but all tests confirmed negative results. The suspicion of isolated involvement of the pericardium was therefore demonstrated by the analysis of cytokines which strongly support our hypothesis.
\end{abstract}

KEY WORDS: COVID-19; cardiac tamponade; cytokines; pericardial drainage; echocardiography; immunoglobulin test anti SARS-CoV-2

\footnotetext{
${ }^{1}$ Department of Anesthesia and Intensive Care Medicine, Academic Hospital of Udine, Piazzale S.M. della Misericordia, 15, 33100 Udine, Italy

${ }^{2}$ Department of Medicine, University of Udine, Udine, Italy

${ }^{3}$ Institute of Clinical Pathology, Department of Laboratory Medicine, Academic Hospital of Udine, Udine, Italy

${ }_{4}^{4}$ Infectious Diseases Clinic, Udine University Hospital, Udine, Italy

${ }^{5}$ To whom correspondence should be addressed at Department of Anesthesia and Intensive Care Medicine, Academic Hospital of Udine, Piazzale S.M. della Misericordia, 15, 33100, Udine, Italy. Email: cristian.deana@ asufc.sanita.fvg.it
}

\section{TO THE EDITOR}

SARS-CoV-2 is a systemic disease, and many different clinical presentations have been seen over the clinical ground [1-3]; this is because the virus binds to the angiotensin-converting enzyme-2 receptor (ACE-2), which is expressed in different organs. As a consequence, this leads to different clinical manifestations extensively described in the last year [4].

Among these, acute respiratory distress syndrome (ARDS) remains predominant and difficult to treat for the intensivist $[5,6]$. 
However, as it regards cardiac involvement, the virus and local cytokine release have been rarely reported and, most of the time, only suspected due to a lack of proof $[7,8]$.

We herein report an acute pericardial effusion with life threatening cardiac tamponade in the context of SARS-CoV-2 infection limited to the heart without other organ's involvement.

A 77-year-old-man was admitted to the emergency department (ED) with atrial fibrillation. A nasopharyngeal swab tested positive for COVID-19 (real-time PCR test). Hemoglobin level at ED admission was $12.4 \mathrm{~g} / \mathrm{dL}$, white blood cell count (WBC) was $5190 / \mathrm{mm}^{3}$, platelets (PLT) were $124.000 / \mathrm{mm}^{3}$, and serum creatinine was $2.17 \mathrm{mg} / \mathrm{dL}$ (stable values).
The patient was a resident in a retirement home due to physical disabilities. He presented with chronic heart failure, arterial hypertension, type 2 diabetes, chronic kidney failure, and chronic obstructive pulmonary disease (COPD) with chronic respiratory failure requiring longterm $\mathrm{O}_{2}$ therapy.

One month before, he was admitted to the hospital for COPD exacerbation. At that time, transthoracic echocardiography did not reveal pericardial effusion. His chronic medications were amiodarone, furosemide, lansoprazole, simvastatin, and insulin.

After point of care ultrasound (POCUS) examination in the ED, pericardial effusion around $1.5 \mathrm{~cm}$ was seen; no B-lines or pleural effusion were detected.

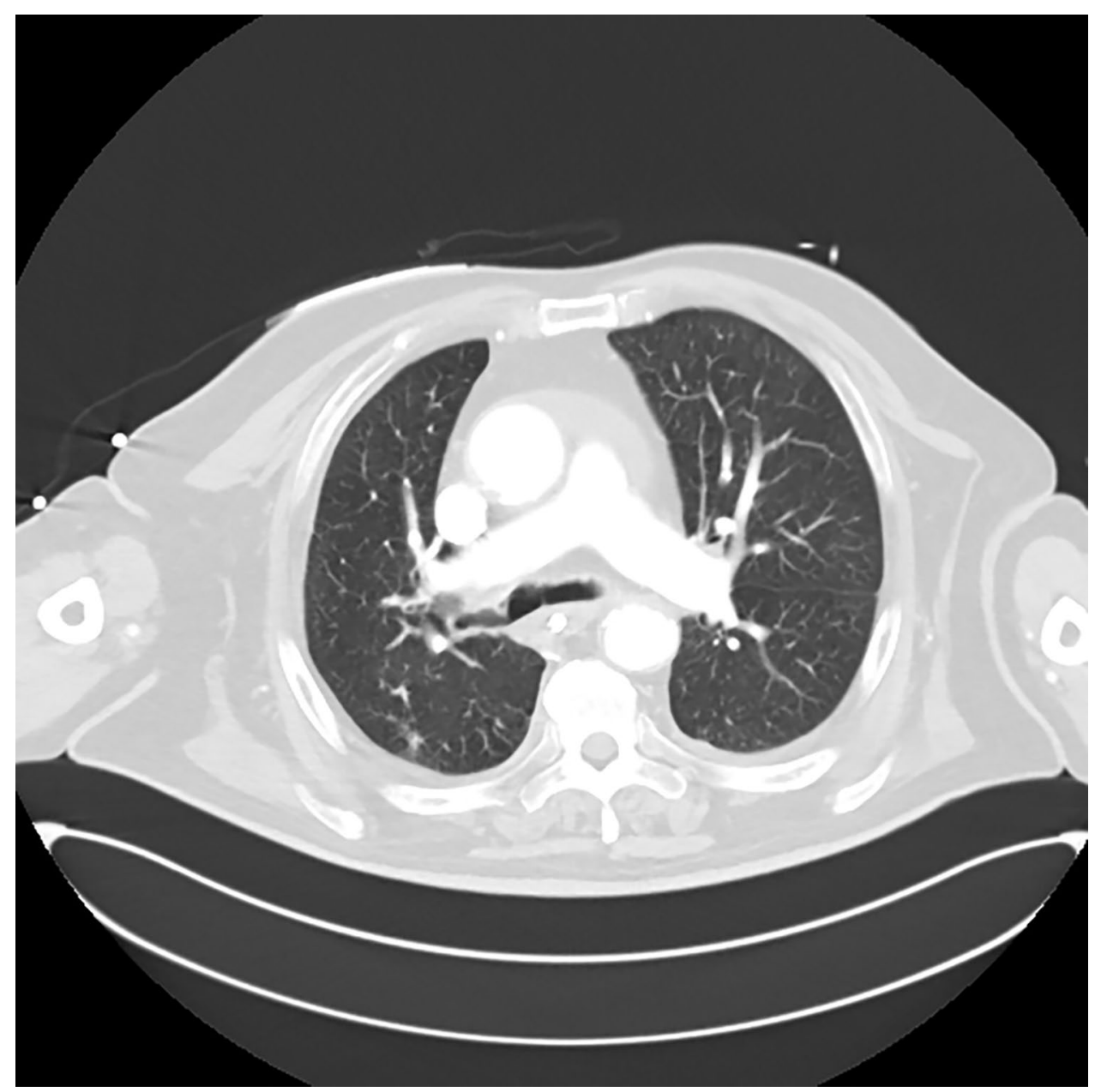

Fig. 1 CT thorax scan. The CT thorax scan did not show any lung involvement by COVID-19, ruling out the possibility of a coexisting coronavirus pneumonia. It also showed no signs of pulmonary embolism. 
The computed tomography (CT) of the thorax excluded pulmonary embolism or lung COVID-19 interstitial pneumonia (Fig. 1).

However, for the development of hemodynamic instability (i.e., low arterial pressure near $85 / 45 \mathrm{mmHg}$, high heart rate of $125 \mathrm{bpm}$, and the need for vasoactive support with noradrenaline $0.30 \mathrm{mcg} / \mathrm{kg} / \mathrm{min}$ ), the patient was admitted to the intensive care unit (ICU). During hospital stay, he was not treated with remdesivir.

A progressive increase in pericardial effusion size was observed in the following hours. Moreover, the signs of impending obstructive shock forced physicians to perform pericardiocentesis and to leave in place a pericardial 6-French "pig-tail" catheter (Fig. 2 and Video 1).

Pericardial fluid was then collected and analyzed. Thus, our case is one of the few cases reported in the literature regarding cytokine concentration measurement (Table 1) within pericardial fluid.

We further analyzed the pericardial concentration of IgG anti-SARS-CoV-2 (CLIA method), with the results showing $101.0 \mathrm{UA} / \mathrm{mL}$ and $25.1 \mathrm{UA} / \mathrm{mL}$ for IgM.

We also tested for other possible causes of cardiac involvement because of systemic disease: antiphospholipid antibodies (anticardiolipin, lupus anticoagulans, antiphosphatidylserine/prothrombin complex antibodies), antinuclear antibodies (indirect immunofluorescence (IIF)) including SSA Ro60, Ro52, SSB, Sm/RNP, Scl-70, PM-SCL, Jo1, centromere, PCNA, dsDNA, p-ribosomal protein, Mi2, ThTo, Ku, RNApolymerase III, anti-neutrophil cytoplasmic antibody (ANCA), and anti-smooth muscle antibodies, which all tested negative.

Quantiferon TB-Plus test was negative. Serum Tn I high sensitivity remained $<78.5 \mathrm{ng} / \mathrm{L}$ during the patient's hospital stay (cutoff value for our laboratory).

Microbiological samples testing bacterial and cytological examination also produced negative results.

After cardiac tamponade resolution with pericardial fluid removal, medical treatment including prednisone of $0.5 \mathrm{mg} / \mathrm{kg}$ and colchicine $500 \mathrm{mg}$ once a day was started.

The patient's symptoms improved, thus leading him to be discharged from ICU after 10 days. He went home 30 days after hospital admission.

To the best of our knowledge, this is the first clinical report that evaluated cytokine concentration and

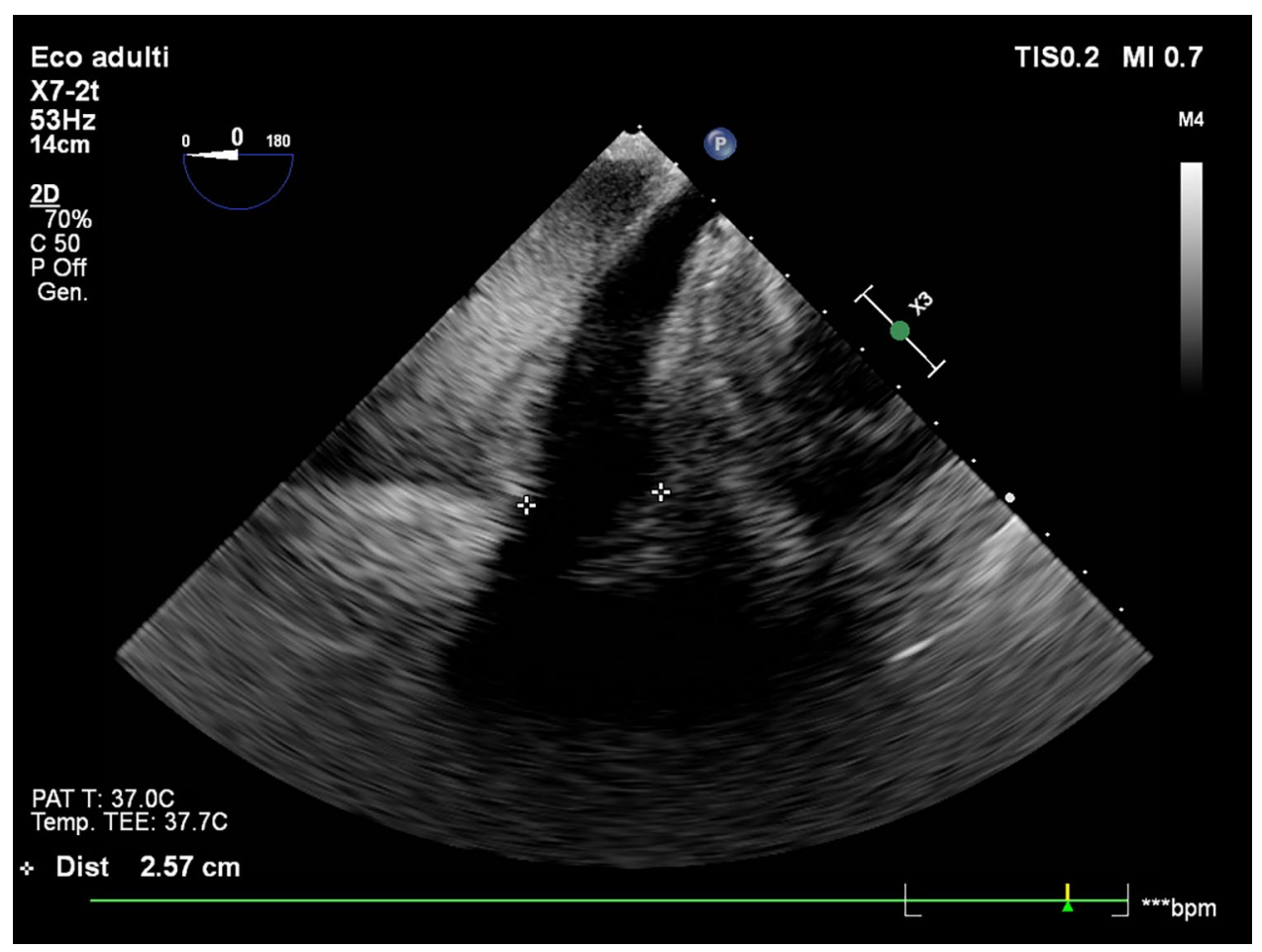

Fig. 2 Transesophageal view of pericardial effusion. Large pericardial effusion about $2.5 \mathrm{~cm}$ around right heart side was detected with transesophageal echography. 
Table 1 Cytokine Levels Comparing Plasma to Pericardial Fluid Values

\begin{tabular}{lll}
\hline Cytokine/test & Plasma values (n. v.) & $\begin{array}{l}\text { Pericardial } \\
\text { fluid values }\end{array}$ \\
\hline IL-1 $\beta(\mathrm{pg} / \mathrm{mL})$ & $0.0(<0.16)$ & 1.1 \\
IL-6 $(\mathrm{pg} / \mathrm{mL})$ & $\mathbf{1 6 . 5}(0.8-6.4)$ & $\mathbf{9 2 2 5}$ \\
IL-8 $(\mathrm{pg} / \mathrm{mL})$ & $\mathbf{3 8 . 5}(6.7-16.2)$ & $\mathbf{2 6 8 7}$ \\
$\mathrm{TNF}-\alpha(\mathrm{pg} / \mathrm{mL})$ & $24.2(7.8-12.2)$ & 17.3 \\
$\mathrm{IL}-10(\mathrm{pg} / \mathrm{mL})$ & $20.1(1.8-3.8)$ & 19.7 \\
$\mathrm{IL}-2 \mathrm{receptor}(\mathrm{pg} / \mathrm{mL})$ & $2329.0(440.0-1435.0)$ & 2780 \\
$\mathrm{IP}-10(\mathrm{pg} / \mathrm{mL})$ & $\mathbf{5 4 4 . 0}(37.2-222.0)$ & $\mathbf{1 1 1 5}$ \\
IFN- $\gamma(\mathrm{pg} / \mathrm{mL})$ & $0.0(<0.99)$ & 1.1 \\
NT pro-BNP $(\mathrm{ng} / \mathrm{L})$ & $758(<300$ rule out; $>1800$ & $\mathbf{2 0 8 6}$ \\
& rule in) & \\
\hline
\end{tabular}

$I L$ interleukin, $I F N$ interferon, $N T$ pro-BNP $\mathrm{N}$-terminal pro-B-type natriuretic peptide

anti-SARS-CoV-2 immunoglobulin levels within pericardial fluid in acute cardiac tamponade.

We hypothesized that in this case, a confined COVID-19 pericardial involvement occurred since no lung disease was seen at the CT-thorax scan. We therefore investigated for other than SARS-CoV-2 causes of pericardial disease such as autoimmune diseases, bacterial (including tuberculosis) or viral infections, acute myocardial infarction, and drug-induced pericarditis [9].

All supposed causes were excluded except SARS-CoV-2 involvement as demonstrated by the high cytokine concentration and $\mathrm{IgG} / \mathrm{IgM}$ levels within the pericardial fluid.

The higher concentration of cytokines, especially IL-6 and IL-8, than blood values, reinforced our suspicion of an inflammation limited to within the heart, more precisely in the pericardium.

SARS-CoV-2 cardiac involvement has been frequently reported, with acute myocardial infarction and pericarditis the most frequently described diseases [10-12]. Also, rare cases of cardiac tamponade have been quoted as a suspected isolated manifestation of COVID-19 infection [13]. However, no strong demonstration has been produced so far. Clinical suspicion of a disease always requires proof in the context of evidence-based medicine, and in this case, lung ultrasound helped us to rule out COVID-19 pneumonia [14, 15].

The underlying pathophysiology is not yet known. However, the mechanism probably involved is secondary to modulation of angiotensin converting enzyme-2 (ACE-2) receptors by COVID-19, which are expressed in the heart, esophagus, kidney, bladder, ileum, as well as the alveoli [16].

In conclusion, we reported a case of a pericardial effusion with life-threatening cardiac tamponade caused by SARS-CoV-2 infection localized in the pericardium.

\section{SUPPLEMENTARY INFORMATION}

The online version contains supplementary material available at https://doi.org/10.1007/s10753-021-01563-3.

\section{AUTHOR CONTRIBUTION}

$\mathrm{CD}$ and LV conceived the study, collected data, analyzed the data, and wrote the manuscript. MF, FC, ES, CT, and FB helped in analyzing data and writing manuscript. All authors read and approved the final version of the manuscript.

\section{DECLARATIONS}

Ethics Approval Ethics approval was waived due to the report of anonymous clinical data.

Consent to Participate Not applicable.

Consent for Publication Written informed consent was obtained from the patient that consented to the submission of the case report.

Conflict of Interest The authors declare no competing interests.

\section{REFERENCES}

1. Cao, Y., Liu, X., Xiong, L., and Cai K. 2020. Imaging and clinical features of patients with 2019 novel coronavirus SARS-CoV-2: A systematic review and meta-analysis. Journal of Medical Virology 92:1449-1459. https://doi.org/10.1002/jmv.25822.

2. Zhu, J., Zhong, Z., Ji, P., Li, H., Li, B., Pang, J., Zhang, J., and Zhao, C. 2020. Clinicopathological characteristics of 8697 patients with COVID-19 in China: A meta-analysis. Family Medicine and Community Health 8(2):e000406. https://doi.org/10.1136/fmch2020-000406. Erratum in: Family Medicine and Community Health 8(2).

3. Deana, C., Verriello, L., and Pauletto, G, et al. 2021. Insights into neurological dysfunction of critically ill COVID-19 patients. Trends in Anaesthesia \& Critical Care 36:30-38. https:// doi.org/10.1016/j.tacc.2020.09.005.

4. Li, J., Huang, DQ., Zou, B., Yang, H., Hui, WZ., Rui, F., Yee, NTS., Liu, C., Nerurkar, SN., Kai, JCY., Teng, MLP., Li, X., Zeng, H., Borghi, JA., Henry, L., Cheung, R., and Nguyen, 
MH. 2021. Epidemiology of COVID-19: A systematic review and meta-analysis of clinical characteristics, risk factors, and outcomes. Journal of Medical Virology 93(3):1449-1458. https:// doi.org/10.1002/jmv.26424.

5. Coopersmith, CM., Antonelli, M., Bauer, SR., Deutschman, CS., Evans, LE., Ferrer, R., Hellman, J., Jog, S., Kesecioglu, J., Kissoon, N., Martin-Loeches, I., Nunnally, ME., Prescott, HC., Rhodes, A., Talmor, D., Tissieres, P., and De Backer, D. 2021. The surviving sepsis campaign: Research priorities for coronavirus disease 2019 in critical illness. Critical Care Medicine 1;49(4):598622. https://doi.org/10.1097/CCM.0000000000004895.

6. Yang, L., X. Xie, and Z. Tu, et al. 2021. The signal pathways and treatment of cytokine storm in COVID-19. Signal Transduction and Targeted Therapy 6:255. https://doi.org/10.1038/ s41392-021-00679-0.

7. Dalen, H., Holte, E., Guldal, AU., Hegvik, JA., Stensaeth, KH., Braaten, AT., Mjølstad, OC., Rossvoll, O., and Wiseth, R. 2020. Acute perimyocarditis with cardiac tamponade in COVID19 infection without respiratory disease. BMJ Case Reports CP 19;13(8):e236218.https://doi.org/10.1136/bcr-2020-236218.

8. Cairns, L., Abed El Khaleq, Y., Storrar, W., and ScheuermannFreestone, M. 2021. COVID-19 myopericarditis with cardiac tamponade in the absence of respiratory symptoms: a case report. Journal of Medical Case Reports 25;15(1):31. https://doi. org/10.1186/s13256-020-02618-z.

9. Adler, Y., Charron, P., Imazio, M., Badano, L., Barón-Esquivias, G., Bogaert, J., Brucato, A., Gueret, P., Klingel, K., Lionis, C., Maisch, B., Mayosi, B., Pavie, A., Ristic, AD., Sabaté Tenas, M., Seferovic, P., Swedberg, K., and Tomkowski, W. 2015. ESC Scientific Document Group. ESC Guidelines for the diagnosis and management of pericardial diseases: The Task Force for the Diagnosis and Management of Pericardial Diseases of the European Society of Cardiology (ESC)Endorsed by: The European Association for Cardio-Thoracic Surgery (EACTS). European Heart Journal 7;36(42):2921-2964.https://doi.org/10.1093/eurheartj/ ehv318.
10. Khalid, N., Chen, Y., Case, BC., Shlofmitz, E., Wermers, JP., Rogers, T., Ben-Dor, I., and Waksman, R. 2020. COVID-19 (SARSCoV-2) and the heart - An ominous association. Cardiovascular Revascularization Medicine 21(8):946-949. https://doi.org/10. 1016/j.carrev.2020.05.009.

11. Ramadan, MS. et al. 2021. Monaldi Hospital Cardiovascular Infection Study Group. Cardiac sequelae after coronavirus disease 2019 recovery: A systematic review. Clinical Microbiology and Infection 23:S1198-743X(21)00335-9. https://doi.org/10.1016/j.cmi. 2021.06.015.

12. Diaz-Arocutipa, C. et al. 2021. Pericarditis in patients with coronavirus disease 2019: A systematic review. Journal of Cardiovascular Medicine (Hagerstown). https://doi.org/10.2459/JCM.0000000000001202.

13. Furqan, MM., Verma, BR., Cremer, PC., Imazio, M., and Klein, AL. 2021. Pericardial diseases in COVID19: A contemporary review. Current Cardiology Reports 3;23(7):90. https://doi.org/ 10.1007/s11886-021-01519-x.

14. Vetrugno, L., Bove, T., Orso, D., Bassi, F., Boero, E., and Ferrari, G. 2020. Lung ultrasound and the COVID-19 "pattern": Not all that glitters today is gold tomorrow. Journal of ultrasound in medicine: official journal of the American Institute of Ultrasound in Medicine 39(11):2281-2282. https://doi.org/10.1002/jum.15327.

15. Deana, C. 2021. The COVID-19 pandemic: Is our medicine still evidence-based? Irish Journal of Medical Science 190(1):1112. https://doi.org/10.1007/s11845-020-02258-8.

16. Ni, W., Yang, X., Yang, D., Bao, J., Li, R., Xiao, Y., Hou, C., Wang, H., Liu, J., Yang, D., Xu, Y., Cao, Z., and Gao, Z. 2020. Role of angiotensin-converting enzyme 2 (ACE2) in COVID19. Critical Care 13;24(1):422. https://doi.org/10.1186/ s13054-020-03120-0.

Publisher's Note Springer Nature remains neutral with regard to jurisdictional claims in published maps and institutional affiliations. 